\title{
Effect of Mingtang Culture Pattern on Architecture Layout of Tang Liuzhou East Pavilion
}

\author{
$\mathrm{Li} \mathrm{He}^{*}$
}

Department of Urban Planning, Zhongkai University of Agriculture and Engineering, Guangzhou, Guangdong, 510225, P.R. China

\begin{abstract}
As an important cultural pattern, Mingtang affected the construction law of generation and inheritance of Chinese ancient architectural form. Further, it is proved that inherent relevance between cultural pattern and Tang Liuzhou East Pavilion. With function of not only post hostel, but education, recreation and landscape, it still shouldered mission of culture dissemination with political, cultural, landscape and living characteristic in mixed functions. According to relevant literature available, post hostel layout under this model influence was preliminarily discussed and offered new perspectives for architecture theory and innovation in new era.
\end{abstract}

Keywords: Architecture landscape, culture pattern, landscape, liuzhou east pavilion in tang dynasty.

\section{INTRODUCTION}

There are many explanations on the shape and structure of Mingtang in Chinese historical literature. Initially it was the monomer building with functions of ancient emperors' bedroom, court and sacrificial offering, which belonged to the multi-bay composite building structure in the categories of etiquette architectures and followed the natural law of seasonal succession, therefore several seasonal living space corresponding to natural laws of were formed in a single building. However, Mingtang has gone beyond the initial prevalence of single building form and gradually formed important influence on layout and structure to the architectural complex during the Sui and Tang Dynasties in its historical development and evolution [1-6].

\section{RESEARCH METHODOLOGIES}

Literature induction, comparison and case analysis were the main research method of this process. Scholars have argued the development process of Mingtang from prosperity to decline and three stages of its form evolution, from ancient three generations to Sui and Tang Dynasties. However, how did the construction entity which originally Kings exclusively owned fade out the monomer form and evolve into civil buildings with "hall" or" platform" for the radial composition? The next followed a few ancient Mingtang typical models as the comparison basis with a case study of post hostel in Tang Dynasty, and also stated how cultural model evolved from single form to the derivation and development law of architectural complex.

\section{PRIMITIVELY ANCIENT CHINA TYPICAL MINGTANG PATTERNS}

According to the historical literatures in the Four Branches of Literature in royal library (Wen Yuan Ge),

\footnotetext{
*Address correspondence to this author at the Department of Urban Planning, Zhongkai University of Agriculture and Engineering, Guangdong, 510225, P.R. China; Tel: 13825051340; E-mail: liv0909@163.com
}

centripetal composition of Mingtang had mainly five forms of type $\mathrm{H}$, five-square type, plum-blossom type, north-south axis and cruciform type (as shown in Fig. 1). Specifically, in each pattern, every shaded block represents a symbolized space (room) of the whole Mingtang and grids on the chart's background offer the sense of distances between every shaded block in order to compare the differences among the patterns. In the literature, Mingtang has the common points in two aspects: The first is with substantial building space for the symmetric form of centralized composition center; Secondly, no matter how its form evolved, monthly climate and season climate reflected revealed its essence was rooted in the farming culture of the Confucian groups in each period of Han Dynasty. It was in the building (group) processing, and the corresponding way of living space to make their own some fit the spirit of the place and the universe and emperors who could induct human and the God etc., which was the primitive worship and obedience to the laws of nature.

\section{ARCHITECTURAL FUNCTIONS AND FORM FEATURES OF TANG DYNASTY POST HOSTEL}

In making sense of the contemporarily Chinese landscape, pavilions just refer to the openly framed structures with roofs, which is a far cry from the ancient ones that used to be termed the same word "pavilion" in a combination of post house and hotel, etc. Precisely, before Tang Dynasty, "Pavilion" has had political, military connotation and significance of Buddhism. For example, in Tang Dynasty poems, Tang Pavilion had borne some specific functions of use of preparing the meal, dressing, banqueting guests, housing guests. Actually that was to use seats, windows and curtains to be as an actual construction to banquet guests without only a simple spot offered to halt and to enjoy the view. Obviously it was an entity with walls, doors, windows and curtains instead of an open pattern. And most of time, it was conceivable that the "Pavilion" meant a group of buildings. 


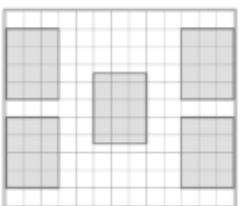

A: THE PATTERN OF TYPE H

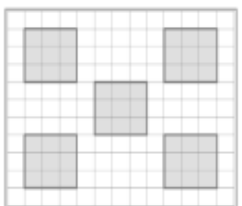

B: THE PATTERN OF FIVE-SQUARE

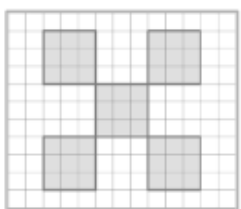

C: THE PATTERN OF PLUN-BLOSSOM

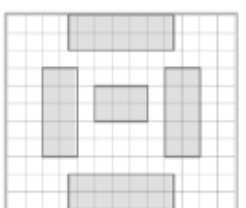

D: THE PATTERN OF NORTH-SOUTH AXIS

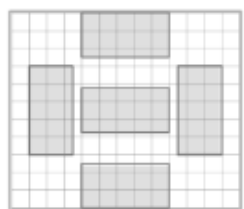

E: THE PATTERN OF CRUCIFORM

Fig. (1). Analysis of morphological types of mingtang

\section{INFLUENCE OF MINGTANG MODE TO LIUZHOU EAST PAVILION LAYOUT}

It would be comparatively controversial that the form of Liuzhou East pavilion in Tang dynasty had been impacted by Mingtang in that it is an architectural complex while Mingtang used to be represented by the single building. This had been actually materialized by a renowned poet in Tang dynasty named Liu Zongyuan owing to the following details.

Historically, Liuzhou East Pavilion is a Tang Dynasty pavilion in the southern border. In Tang Yuanhe 12th year (817) September, Liu Zongyuan wrote "Liuzhou East Pavilion Notes", which described its surrounding environment, construction process and design characteristic in the architectural art. The former part showed it was not a pure landscape architectural. As the post hostel with land and water combination, it contained East Hostel (to provide accommodation, receive guests who would have an audience with the emperor, and offer vehicles for them; Posthouse (assuming the document-transfer purpose as "pass" or "hostel", namely the post ride transfer hall) and Five Rooms (in the center, partly standing between the two post buildings and being partly incorporated by the former two). The construction site of East Pavilion, as shown in Fig. (2), was although far from Mingtang single building image, the architectural layout of form and content was deeply influenced by it. Like Five Rooms of East Pavilion, Sun-up Room 'Yin Room from the Chinese-style rooftop of East Hostel, Yang Room in front of Northern Wall, Sunset Room in the east of hostel and north of rooftops, as shown in Fig. (3), the form layout of its location and orientation has been greatly broken through from the old system, retaining and kept only the centripetal and middle Tang pavilion composition; However, the content was strictly reflected on the tenet "Behavior should adapt season and never violate it, "and coordinated with "In accordance with the laws of development of things.

Essentially, Five Rooms of East Pavilion were by "regulation of seasonal living" to choose the room and agree with Chinese classical literature "monthly living" in the Zhou Dynasty Mingtang chart. From form to content, it was in line with the general composition feature and spiritual connotation, which reflected the abstract Mingtang of "Behavior should adapt season".

\section{COORDINATION OF LIUZHOU EAST PAVILION ON REGIONAL CLIMATE AND MULTIPLE FUNC- TIONAL MIXED CHARACTERISTIC}

Liu Zongyuan got the serious health damage after his arrival in Liuzhou for climate did not suit him. Functional layout of "Cool Room doesn't meet warm wind and Sunny
Room is against cool wind" was just his urgent requirement that spontaneously formed against the Liuzhou water and soil because building space and ecological environment of Five Rooms were closely blended. As the Tang post hostel was the enclosed space entity where officials could entertained and every room had the exact function. Except Middle Room, each room directly faced the direction corresponding to the opening: Positive Room directly faced the east in which opening doors and windows which could accept direct sunshine; Yin Room, opening directly to the north, was in order to get dry and cool north wind; Sunset Room and Sunup Room were completely open only to the corresponding direction, and other directions were all in the eaves shadow or down the walls. In addition, Five Rooms of East Pavilion had the functions of the public space, firstly being the combination of Mingtang layout to meet the political civilization, secondly being to meet the requirements of local officials in his spare time "catering leisure". These two points were East Pavilion's different features from others. Mingtang-style composition for Five Rooms of East Pavilion was most likely in its cultural value dissemination.

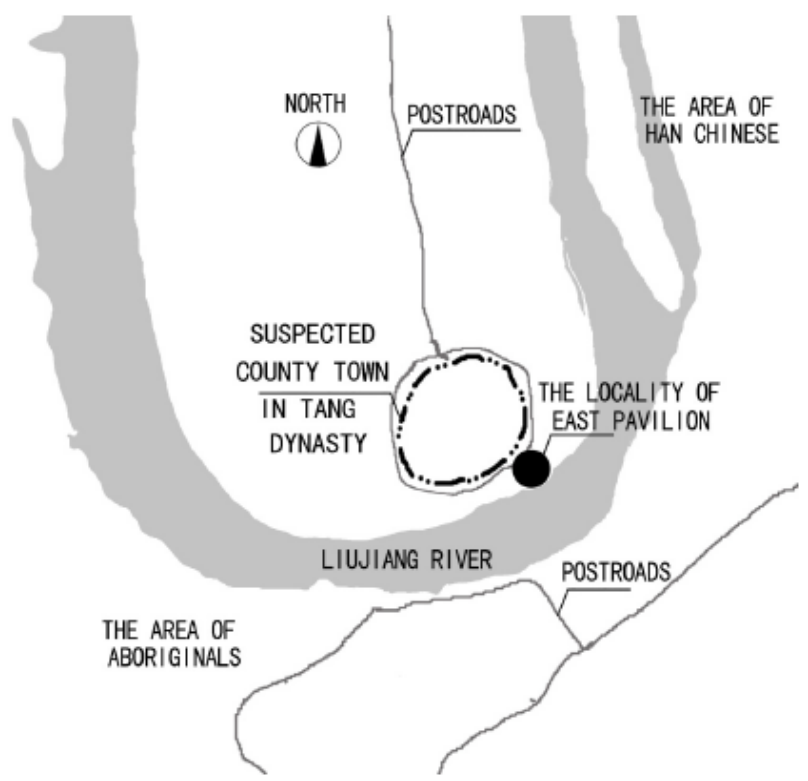

Fig. (2). Liuzhou east pavilion in tang dynasty "construction siteenvironment" relationship analysis chart.

\section{ANALYSIS OF PLANE LAYOUT OF LIUZHOU EAST PAVILION}

Combining the results of previous studies on post hostel building, this paper attempts to restore the building layout of Tang Liuzhou East Pavilion, as shown in Fig. (3), Five 


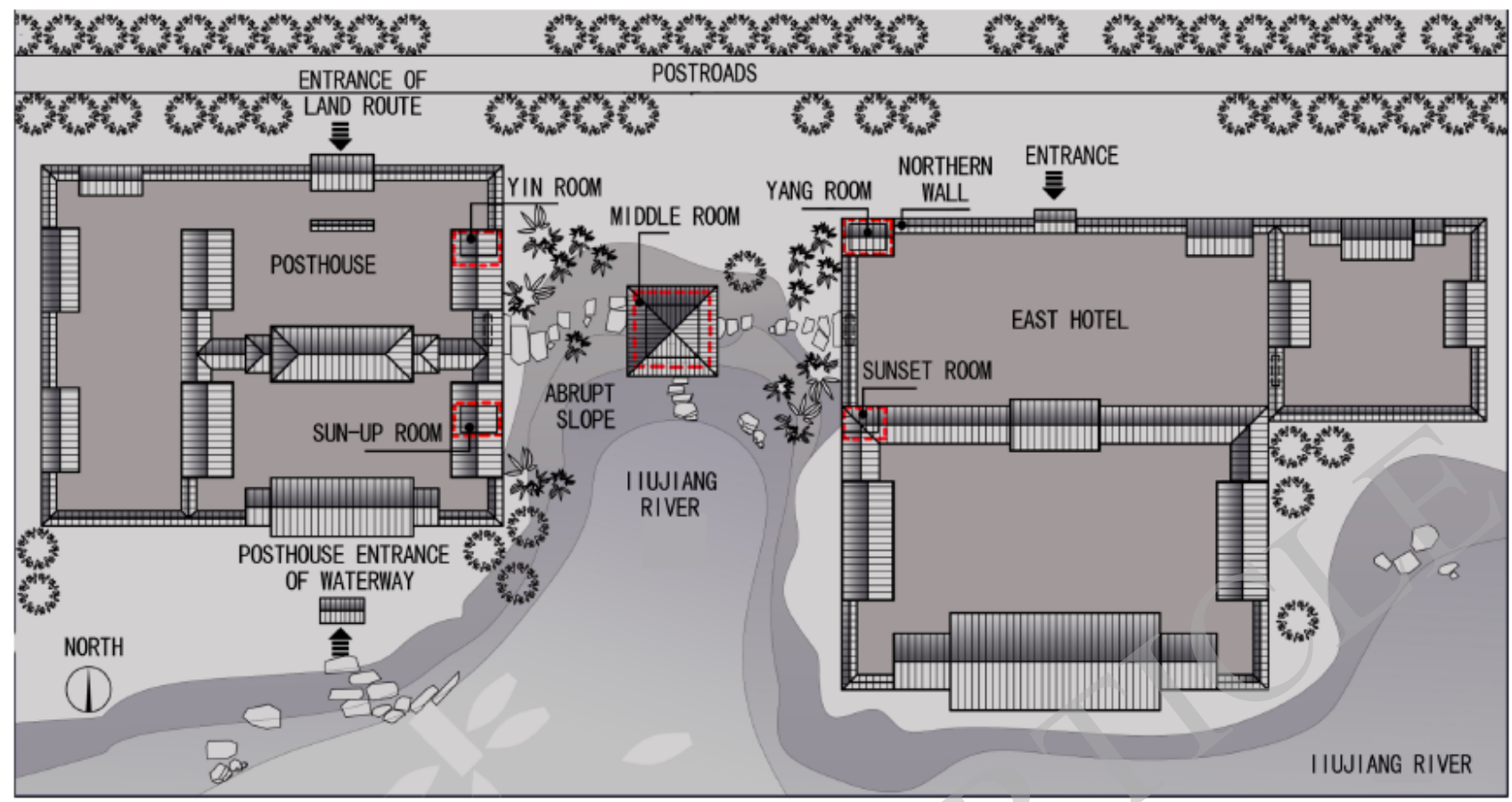

Fig. (3). Liuzhou east pavilion five rooms layout analysis chart.

Rooms were in the middle location. East Pavilion was far from the old sites of two extensive blocks, so Five-Room layout was far from the north-south axis of Mingtang and very difficult to achieve the "five-square" and "plumblossom type" with the same distance requirements in all directions, therefore, it might be more partial " $\mathrm{H}$ " type layout of Zhou Dynasty Mingtang. Wall type "Northern Wall" existed in the eastern wing nearby and Yang Room was built in the post hotel adjacent to the "Northern Wall". The scales of each room in addition to Middle Room could be referred to Zhou Dynasty "Every room covered areas equal to the size of two mats (Xi)" in Chinese classic literatures.

\section{CONCLUSION}

Mingtang began to gradually decline for "Without compliance with the old style for evolution, do what others have never done before to be suitable for things" in the middle of Tang Dynasty. Many examples of ancient buildings no longer confined to Five Rooms layout, five ranges had been abstracted into symbolic. The layout of building groups were in accordance with the Mingtang abstraction. Overall, Liuzhou East Pavilion is a group including Post House, Post Hostel and Five Rooms, at the same time also had the etiquette culture communication and catering leisure function of Mingtang style.

\section{CONFLICT OF INTEREST}

The authors confirm that this article content has no conflict of interest.

\section{ACKNOWLEDGEMENTS}

This work was financially supported by Natural Science Foundation of China (nos. 51208528).

\section{REFERENCES}

[1] Zhang Shizhao. Liu Wen Zhi Yao - Ti Yao Zhi Bu "Ji" (volume twenty-nine volume), Beijing, 1971, pp.856.

[2] Li Guohao Jian Yuan Shiying -- China Ancient Civil Construction Technology of Historical Compilation (the first chapter Kao Gong Dian-Post Hostel Part), Shanghai, 1990, pp.57.

[3] C. Jiaqi, Song Dynasty Traffic Management System Research, Kaifeng, 2002, pp.12-14.

[4] Wang Guixiang. Eastern and Western Architectural Space: the Traditional Chinese and Medieval Western Architecture Culture Interpretation,,Tianjin, 2006 ,pp.182-214.

[5] Four Branches of Literature in royal library (Wen Yuan Ge) - the Original and Full-text Retrieval Edition), Shanghai: Shanghai People's Publishing House Dizhi Culture Publishing Company, 1999. [E book] Available From: Wen Yuan Ge e-book.

[6] Li Yunhe. Artistic Conception of Chinese, Tianjin, 2005, pp.100.

Received: January 18, 2015

Revised: March 09, 2015

Accepted: April 07, 2015

(C) Li He; Licensee Bentham Open.

This is an open access article licensed under the terms of the (https://creativecommons.org/licenses/by/4.0/legalcode), which permits unrestricted, noncommercial use, distribution and reproduction in any medium, provided the work is properly cited. 